NASA Technical Memorandum 102117

AIAA-89-2727

\title{
Modeling of Pulsed Propellant Reorientation
}

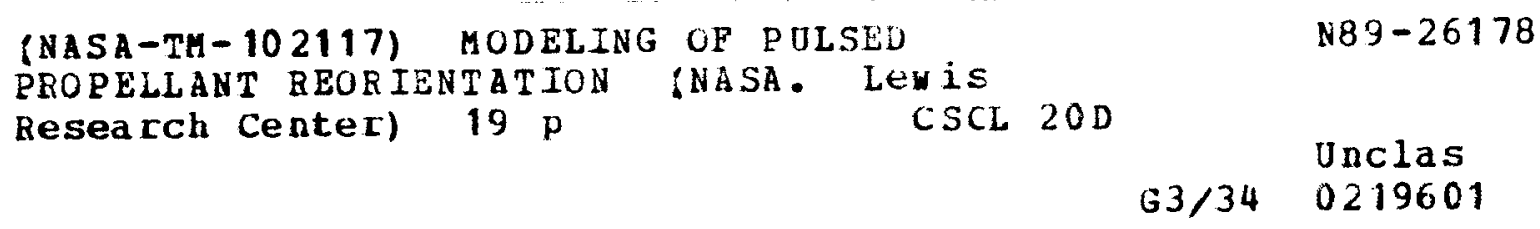

\begin{abstract}
Washington University
St. Louis, Missouri

and

D.J. Chato

Lewis Research Center

Cleveland, Ohio
\end{abstract}

A.E. Patag and J.I. Hochstein

Prepared for the

25th Joint Propulsion Conference

cosponsored by the AIAA, ASME, SAE, and ASEE

Monterey, California, July 10-12, 1989 


\title{
MODELING OF PULSED PROPELLANT REORIENTATION
}

\author{
A.E. Patag and J.I. Hochstein \\ Washington University \\ St. Louis, Missouri \\ and \\ D.J. Chato \\ National Aeronautics and Space Administration \\ Lewis Research Center \\ Cleveland, Ohio 44135
}

\begin{abstract}
Optimization of the propellant reorientation process can provide increased payload capability and extend the service life of spacecraft. This paper proposes the use of pulsed propellant reorientation to optimize the reorientation process. The ECLIPSE code has been validated for modeling the reorientation process and is used to study pulsed reorientation in small-scale and full-scale propellant tanks. A dimensional analysis of the process is performed and the resulting dimensionless groups are used to present and correlate the computational predictions for reorientation performance.
\end{abstract}

\section{INTRODUCTION}

During coast in Low-Earth-Orbit (LEO), liquid propellants can collect in the forward end of a spacecraft propellant tank due to atmospheric drag. To preclude vapor ingestion by the engine, a propellant acquisition system is required to assure that sufficient liquid will be positioned over the tank outlet prior to main engine firing. Passive acquisition systems typically provide channels and baskets inside the tank and rely on surface tension to hold liquid in the desired position within the structures. These structures add complexity to the design and increase the launch weight of the spacecraft. Active acquisition requires the firing of auxiliary thrusters to accelerate the vehicle and is usually referred to as impulsive reorientation or settling. The acceleration vector is oriented so that the induced relative motion between the propellant and the tank positions a pool of liquid over the main tank outlet. Since each reorientation maneuver requires the expenditure of propellant, optimization of the settling process can increase payload capability and extend spacecraft service life.

Existing studies of impulsive reorientation have focused on settling performance under the influence of a constant imposed acceleration. For a steady acceleration applied to the propellant tank, the standard practice (Reynolds and Satterlee, 1) for computing the time required to settle propellant is based on the following equation derived from a rigid body dynamics analysis:

$$
T_{s}=(\tau)(2 \mathrm{~L} / \mathrm{a})^{1 / 2}
$$

where $(\tau)=$ the number of times the tank accelerates past the liquid

$\mathrm{T}_{\mathrm{s}}=$ settling time, $\mathrm{s}$

$L^{s}=$ tank length, cm

$\mathrm{a}=$ imposed acceleration, $\mathrm{cm} / \mathrm{s}^{2}$ 
An estimate of the time required for safe engine firing is obtained by using $($ tau $)=5$. For complete propellant settling, $(\tau)=10$.

The retentive property of surface tension provides a region of stability in which the liquid-vapor interface remains static under the influence of gravitational or acceleration-induced forces. For certain low values of Bond number, there exists a curved interface which is a position of stable equilibrium. For the case of vertical, cylindrical walls and zero contact angle, numerical analyses performed by Bretherton (2)* and Gluck and Gille (3) computed the critical Bond number to be less than 0.842 for hydrostatic stability.

The vehicle velocity increment or delta-V incurred during the reorientation maneuver is a good measure of performance since it is proportional to the propellant expenditure required to complete the maneuver (4). Using vehicle delta-V as the criteria, Sumner (4) concluded that optimal settling would occur for low Bond numbers between 3 to 5 for the configurations evaluated in the study. This reference also presented an empirically based method for computing settling performance.

Pulsed settling provides the possibility of standard thruster sizes for a variety of spacecraft and optimal acceleration levels for the duration of an entire mission. Even if auxiliary thrusters are customized for each hardware configuration, they cannot provide the optimal conditions for the entire mission. As propellant is depleted, the tank filling changes and so does the optimal acceleration leve1. The key idea behind pulsed reorientation is to use the propellant's inertia to integrate the impulses provided by intermittent thruster firing to provide a desired "effective" acceleration level. For pulsed settling, a relationship analogous to Equation (1) is derived in Patag (5):

$$
T_{s}=n / f_{p}
$$

where $\mathrm{n}=$ the number of cycles required to achieve reorientation

$$
f_{p}=\text { thrusting frequency, } \mathrm{Hz}
$$

A literature review revealed no previous investigations of pulsed reorientation. Experimental study of this proposal is extremely difficult since it requires simultaneous modeling of inertia, viscous, and surface tension forces in a time dependent environment. By contrast, the ECLIPSE Code provides a suitable tool for evaluating the performance of pulsed reorientation. Its accuracy in modeling impulsive reorientation due to the steady firing of thrusters has been demonstrated by Hochstein et al (6). It can be used to model small-scale drop tower experiments and small-scale flight experiments as well as full-scale spacecraft tanks.

The results reported in this paper are for a sequence of "typical" OTV tanks. The development of the ECLIPSE Code has been closely coupled to the other projects being pursued under the reduced gravity fluid management technology program sponsored by NASA LeRC. The sequence of tanks reflects the 
evolution of a flight experiment designed to study a variety of fluid management technology issues.

\section{ECLIPSE CODE}

The ECLIPSE code is being developed to model the fluid dynamic, heat transfer, and thermodynamic processes associated with cryogenic propellant management in a reduced gravity environment. It is based on NASA-VOF2D (7), a computer program designed for solving laminar two-dimensional, transient flows with free surfaces. It models incompressible flows with free boundaries using the Volume-Of-Fluid (VOF) method and can accommodate multiple free surfaces. NASA-VOF2D includes models for surface tension and wall adhesion $(7,8)$. It also includes a partial cell treatment for modeling curved boundaries and internal obstacles.

Although ECLIPSE now contains heat transfer and thermodynamic models $(9,10)$, only minor modifications to the baseline code were required to study impulsive reorientation. Variables have been added to permit the investigator to specify a time-dependent acceleration environment and output files are generated specifically to help track the reorientation process. The accuracy of ECLIPSE in modeling the impulsive reorientation process has been documented by comparison to the experimental data for small-scale tanks $(5,6)$.

\section{TERMINOLOGY}

Pulsed settling refers to the process of 1 iquid repositioning due to intermittent firing of auxiliary thrusters. Upon thrust initiation, the liquid leading edge travels smoothly along the tank walls. As it reaches the bottom of the tank a pool of propellant forms. The criterion for reorientation or settling time, $T_{s}$, is defined in this study as the time it takes for the propellant leading edge to reach $20 \%$ of the tank height as measured from the outlet end along the tank centerline. The velocity increment, or delta-V is the proposed measure for propellant consumption. It is the change in vehicle velocity between thrust initiation and satisfaction of the settling criterion.

\section{IMPULSIVE SETTLING: SPACE BASED OTV}

One application of current interest to NASA is the settling of liquid propellant in an Orbit Transfer Vehicle (OTV). The conceptual OTV, as its name implies, will be used as a space "tug," therefore requiring numerous engine restarts. Two Boeing OTV propellant tank prototypes (11) were modeled in this study. The first is the Boeing Space-Based (SB) OTV. The second tank is the Boeing Short SB OTV with elliptical heads.

Hochstein et. al. (6) presented a series of analyses on the reorientation of propellant in these tanks using the ECLIPSE code. A representative case from their paper is reproduced here for comparison. Figure 1 presents the mesh used by them to represent a 0.25 scale model of the SB OTV fuel tank with a liquid hydrogen fill level of $50 \%$. Figure 2 shows the reorientation of propellant in this tank using thrust levels predicted to be 
optimum by the work of Sumner (4). Only a moderate geyser is formed and after approximately 100 seconds the fluid is settled.

\section{PULSED SETTLING: SPACE BASED OTV}

The remaining question is how to achieve this optimal low-level thrust given the minimum acceleration capability of most spacecraft thrusters. (The space shuttle auxiliary RCS thrusters with thrusts of $7.85 \mathrm{~cm} / \mathrm{sec}_{2}$ were used as representative.) A viable solution is to operate the thrusters in an intermittent mode. The parameter values used for this part of the study are shown in Table 1. The 0.25 scale SB OTV tank was again modeled using a propellant fill level of $50 \%$. At this point in the analysis, NASA suggested keeping the same fineness ratio of 1.4 , but changing the hemispherical tank heads to elliptical. An acceleration magnitude of $7.85 \mathrm{~cm} / \mathrm{sec}^{2}$ was combined with pulse durations of 0.1 and 0.2 seconds over a thrusting frequency range of 0.1 to $1.5 \mathrm{~Hz}$.

Figure 3 shows bulk liquid motion resulting from the application of a $7.85 \mathrm{~cm} / \mathrm{sec}^{2}$ thrust for a duration of 0.1 seconds at a frequency of $0.1 \mathrm{~Hz}$. The liquid can be seen to move smoothly down the tank wall, forming a small geyser without any vapor entrainment. The settling criterion was satisfied within 60 seconds of thrust initiation. For this case delta-V $=4.0 \mathrm{~cm} / \mathrm{sec}$. Figure 5 displays the code prediction when the thrusting frequency level is increased to $0.7 \mathrm{~Hz}$. The reorientation criterion was met within 20 seconds. However, the delta-V to accomplish settling is now $10.5 \mathrm{~cm} / \mathrm{sec}$, more than double that of the previous case. Examining the propellant motion, it can be seen that the leading edge progresses smoothly along the wall. A large geyser is formed, indicating excessive energy imparted to the fluid. A similar sequence of flow fields can be seen in Figure 5. For this case, frequency was increased to $1.4 \mathrm{~Hz}$. The liquid reoriented in less than 14 seconds, yielding a delta-V value of $14.8 \mathrm{~cm} / \mathrm{sec}$. Severe geysering and violent surface foaming can be observed, again indicating inefficient reorientation.

The question arose as to what would happen if, for the same acceleration level, the thrust duration was doubled and the thrusting frequency was correspondingly halved. In response to this query, Figure 6 presents 1 iquid motion due to a 0.2 second pulse duration and a $0.7 \mathrm{~Hz}$ thrust frequency. Comparing this bulk propellant motion with the case illustrated in Figure 5, it can be seen that the liquid motion is similar. This simulation resulted in reorientation time of 13.2 seconds and delta-V of $14.5 \mathrm{~cm} / \mathrm{sec}$. These values are almost identical to the results of the case illustrated in Figure 5 .

The balance of the frequency range from 0.1 to $1.5 \mathrm{~Hz}$ was studied using pulse durations of 0.1 and 0.2 seconds. Settling time and delta-V values were recorded for each case. A plot of settling time versus thrusting frequency is shown in Figure 7. Two other curves were added to the plot representing calculations performed using the equations 1 and 2 (4) for settling time.

Figure 7 shows that the equations 1 and 2 over predicts the settling time. It also shows that the same reorientation time may be achieved by a combinations of pulse duration and thrust frequency which satisfy the condition: 


$$
a\left(t_{p 1}\right) f_{p 1}=a\left(t_{p 2}\right) f_{p 2}
$$

where $\mathrm{a}=$ imposed acceleration, $\mathrm{cm} / \mathrm{s}^{2}$

$t_{p}=$ pulse duration, $s$

$f_{p}^{p}=$ thrusting frequency, $\mathrm{Hz}$

This condition is satisfied by values derived from equation 2 as well. Figure 8 shows a graph of settling time versus delta-V. As the settling time decreases, more energy is expended as represented by an increase in delta-V. For low frequency values, changes in delta-V values are small relative to changes in $\mathrm{T}_{\mathrm{s}}$ values. The converse is true for the higher frequency range.

\section{PULSED SETTLING: SHORT SPACE BASED OTV}

Redesign led to the Short SB OTV, the dimensions of which are shown in Figure 9. Analyses were performed using full and 0.215 scale tank models in order to gain insight into liquid behavior during pulsed settling. Areas of particular interest were liquid behavior in both high and low frequency ranges, and effects of acceleration magnitude, pulse duration, fill level, and tank scaling on reorientation time. The parameter values used are shown in Table 1. Thrust levels between $10^{-3}$ and $10^{-4} \mathrm{~g}$ were studied. Pulse durations used were 0.1 and 0.2 seconds. Fill levels of $25 \%, 50 \%$, and $70 \%$ were examined.

Figure 10 is a plot of $T_{s}$ versus frequency for the full scale Short SB OTV propellant tank with a fill level of $50 \%$. At the low frequency ranges, surface tension forces are more predominant, thereby causing erratic behavior of the propellant. Four distinct curves can be seen representing four permutations of pulse duration and acceleration magnitude. Figure 11 shows a plot of $T_{s}$ versus delta- $V$ for full scale and 0.215 scale tanks. Similar to Figure 8 , the values of $T_{s}$ are higher and are more sensitive to changes in values of delta-V at the low frequency ranges, i.e., low values of delta-V. The curve appears to be flattening out as higher values of delta-V are approached. Ultimately, combinations of thrust, frequency, and pulse duration will approximate steady acceleration. Settling time will therefore approach a minimum value corresponding to the application of a steady thrust. For the same acceleration level, delta-V values are equal for combinations of pulse duration and thrusting frequency satisfying Equation 3. An equivalent acceleration can be defined

$$
a_{e}=a\left(t_{p}\right) f_{p}
$$

where $a_{e}=$ effective acceleration, $\mathrm{cm} / \mathrm{s}^{2}$

Equation 3 can be rewritten as

$$
a_{\mathrm{e} 1}=a_{\mathrm{e} 2}
$$

Equation (5) states that for equal values of effective acceleration, propellant consumption required to accomplish reorientation is equivalent. 
In Figure 12, delta- $V$ is plotted against $a_{e}$ for both full and 0.215 scale tank models with fill levels of $50 \%$. As can be seen from the plot, for all cases associated with the full scale tank, if the same $a_{e}$ is used, delta-V values will be identical. The same result holds true for all cases modeling the 0.215 scale tank. Thus, the performance of the full-and small-scale tanks can be represented by a single curve for each tank.

\section{DIMENSIONAL ANALYSIS}

Several numerical groupings were evaluated in attempts to nondimensionalize and thereby collapse the data for reorientation time. The most successful grouping which emerged from this search is presented in Equation 6.

$$
T_{s}^{*}=\left(T_{s} / R\right) *\left(a_{e} * h\right)^{1 / 2}
$$

This group was derived by analogy to $\mathrm{Fr}$ number where a characteristic velocity is divided by a representative acceleration. Figure 13 shows a plot of delta- $V$ versus $T_{s}{ }^{*}$. The $T_{s}{ }^{*} v a l u e$ increases as delta- $V$ varies from approximately 0 to $\$ \mathrm{~cm} / \mathrm{sec}$. The curves for all three fill levels then "spike" upwards at $T_{s}^{*}=1.4$. As can be seen, values appear at the base on both sides of the peak. For low frequencies, small variations in a result in large variations in $\mathrm{T}_{s}^{*}$. Although intuition leads to the hypothesis that higher settling times may be expected for $T_{s}^{*}>1.4$, this is not always true. For $T_{s}^{*}$ values greater than 1.4 , a closer review of the data reveals that $T_{s}$ is high coupled with relatively high values of $a_{e}$. For lower values of $T_{s}^{*}$, relatively small $a_{e}$ are coupled with again high values of $T_{s}$. What is presumed to be happening is that the fluid oscillates due to opposing surface tension forces thereby resulting in a longer reorientation time. Examination of Bond numbers for flows with delta-V values close to zero reveal that operation is near, and at times, even below Bo critical based on steady acceleration studies.

To get a better understanding of $\mathrm{T}_{s}{ }^{*}$, two cases which occur in the vicinity of the spike were examined. For values of $T_{s}^{*} \leq 1.41$, but in the vicinity of the spike, all tests predicted the formation of a small to moderate geyser without any vapor entrainment or any undesirable fluid motion. This indicates efficient reorientation. Figure 14 shows predicted liquid motion for Case 1. The full-scale tank has a fill level of $70 \%$ and is accelerated at $10-3 \mathrm{~g}$ for a 0.2 second duration at $f_{p}=0.040 \mathrm{~Hz}$. The fluid is seen to form a moderate geyser with relatively small liquid velocities. The value of $T_{s}^{*}$ is 1.41 for this simulation. Keeping all other parameters constant, increasing the frequency results in severe geysering as shown in Figure 15 for Case 2. Although fluid velocities are similar to Case 1, excess energy has been imparted to the fluid causing the geyser to rebound off the top of the tank. Settling time is lower but $T_{s}^{*}=1.45$. Based on these evaluations, it appears desirable to operate in the area to the left of the spike.

For $T_{s}^{*}$ less than, but in the vicinity of 1.4 , liquid for both fullscale and small-scale tanks is predicted to form a small geyser. Most of the predictions having higher values of $T_{s}^{*}$ are for a fill level of $25 \%$. Figure 16 shows propellant motion in a small-scale tank with a $25 \%$ fill level. This 
particular simulation yielded $T_{s}^{*}=5.59$. A thin film of liquid moves down along the tank wall. Prior to satisfying the reorientation criteria (20\% of tank length), most of the fluid had been collected at the tank bottom. If the reorientation criteria had been defined at $0.1 \mathrm{~L}$ instead of $0.2 \mathrm{~L}$, sett 1 ing times for all fill levels, though not proportional, would have been reduced greatly. Reviewing the input parameters of $\mathrm{T}_{s}^{*}$, lower settling times would presumably reduce the data scatter resulting in a more definite spike in Figure 14.

\section{SUMMARY}

The propellant reorientation process associated with pulsed firing of auxiliary thrusters has been studies using computational predictions provided by the ECLIPSE code. The analyses included both small-scale and full-scale tanks and were performed for a range of fill levels. A square-wave pulse was assumed and the magnitude, duration, and frequency of the pulse was varied to study the effect of these parameters on reorientation performance. The predicted performance is displayed as velocity field sequences for selected cases and summarized in plots of vehicle delta-V vs. frequency and settling time vs. frequency. It is concluded that, except at very low effective acceleration levels, combination of pulse duration, frequency, and magnitude which result in equal values of effective acceleration produce the same reorientation performance.

The results of the computational predictions were used to test the validity of using proposed dimensionless groups for modeling the pulsed reorientation process. One group, $\mathrm{T}_{\mathrm{s}}{ }^{*}$, appears to collapse all of the data when plotted against vehicle delta- $V$. The value of delta-V spikes upward as a value for $T_{s}^{*}$ of 1.4 is approached from below. Review of predicted flow fields indicates that this corresponds to formation of geysers which indicates inefficient reorientation. It is therefore proposed that configurations which produce values of $\mathrm{T}_{\mathrm{s}}{ }^{*}$ less than, but close to, 1.4 are highly desirable. Reorientation is accomplished relatively quickly for a low expenditure of auxiliary thruster propellant.

\section{REFERENCES}

1. Reynolds, W.C. and Satterlee, H.M., "Liquid Propellant Behavior at Low and Zero-G," Dynamic Behavior of Liquids in Moving Containers, NASA SP-106, 1966, pp. 387-439.

2. Bretherton, F.P., "The Motion of Long Bubbles in Tubes," Journal of Fluid Mechanics, Vol. 1, Mar. 1961, pp. 166-188.

3. Gluck, D.F. and Gille, J.P., "Fluid Mechanics of Zero-G Propellant Transfer in Spacecraft Propulsion Systems," SAE Paper 862A, Apr. 1964 (Also, Journal of Engineering for Industry, Vol. 87, 1965, pp. 1-8). 
4. Sumner, I.E., "Liquid Propellant Reorientation In a Low Gravity Environment," NASA TM-78969, 1978.

5. Patag, A.E., "Pulsed Settling For Low Gravity Liquid Propellant Reorientation," Masters Thesis, Washington University, St. Louis, MO, 1988.

6. Hochstein, J.I., Patag, A.E., and Chato, D.J., "Modeling of Impulsive Propellant Reorientation," AIAA Paper 89-0628, Jan. 1989 (NASA TM-101440).

7. Torrey, M.D., Cloutman, L.D., Mjolsness, R.C., and Hirt, C.W., "NASA-VOF2D: A Computer Program for Incompressible Flows with Free Surfaces," Los Alamos Scientific Laboratory Report LA-10612-MS, Dec. 1985.

8. Nichols, B.D., Hirt, C.W., and Hotchkiss, R.S., "SOLA-VOF: A Solution Algorithm for Transient Fluid Flow with Multiple Free Boundaries," Los Alamos Scientific Laboratory Report LA-8355, Aug. 1980.

9. Hochstein, J.I., Ji, H.-C., and Aydelott, J.C., "Effect of Subcooling on the On-Orbit Pressurization Rate of Cryogenic Propellant Tankage," AIAA Paper 86-1253, June 1986.

10. Hochstein, J.I., Ji, H.-C., and Aydelott, J.C., "Temperature Fields Due to Jet Induced Mixing in a Typical OTV Tank," AIAA Paper 87-2017, June 1987.

11. "Orbital Transfer Vehicle Concept Definition and Systems Analysis Study, Vol. 1, Executive Summary," NASA CR-178866, 1986.

TABLE I. - TEST PARAMETERS

\begin{tabular}{|l|r|r|}
\hline Parameters & Boeing SB 0TV & Boeing short SB OTV \\
\hline Fill leve1, \% & 50 & $25,50,70$ \\
Propellant & Liquid hydrogen & Liquid hydrogen \\
a, cm/sec & 7.85 & $9.81 \times 10^{-1}, 9.81 \times 10^{-2}$ \\
$\mathrm{t}_{\mathrm{p}, \mathrm{sec}}$ & $0.1,0.2$ & $0.1,0.2$ \\
$\mathrm{f}_{\mathrm{Hz}} \mathrm{Hz}$ & 0.100 to 1.500 & 0.001 to 4.000 \\
Settling criteria, L & 0.25 scale & Full, 0.215 scale \\
Tank size & &
\end{tabular}




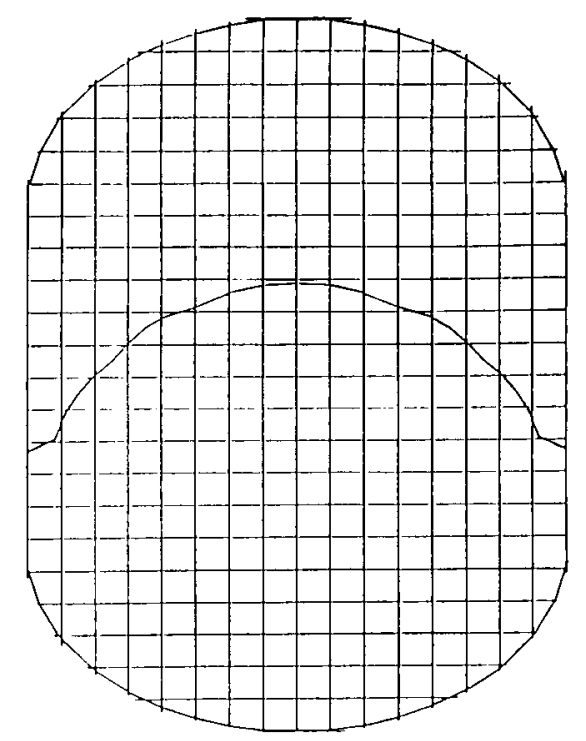

FIGURE 1. - BOEING SB OTV PROPELLANT TANK. 0.25 SCALE. FINENESS RATIO $=1.4: \mathrm{L}=$ $146.69 \mathrm{cM} ; \mathrm{D}=106.68 \mathrm{~cm}$.

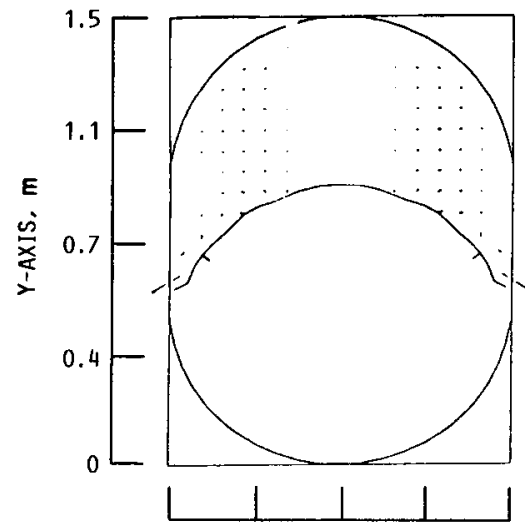

(a) $0.001 \mathrm{sEC}$.

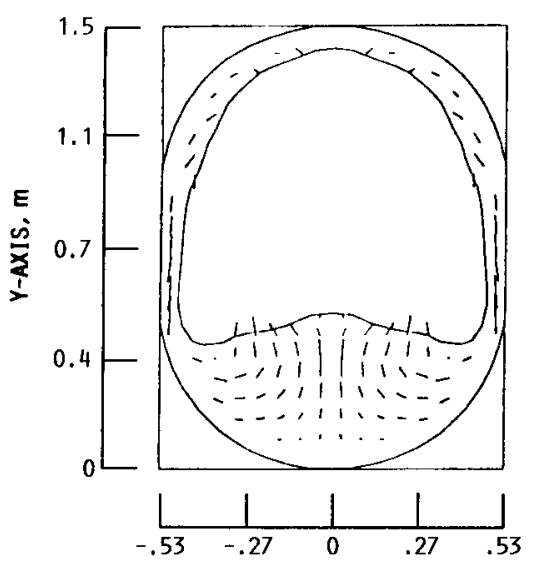

(c) $100 \mathrm{sEC}$.

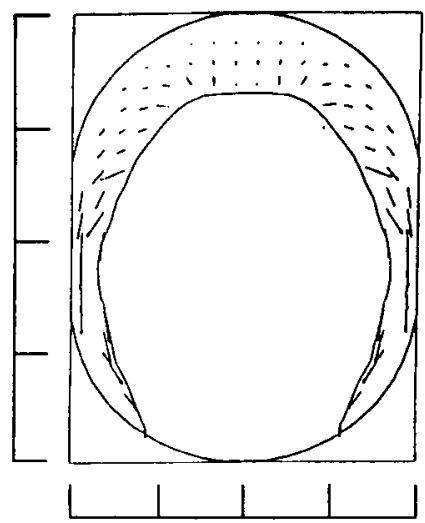

(a) $60.0 \mathrm{sEC}$.

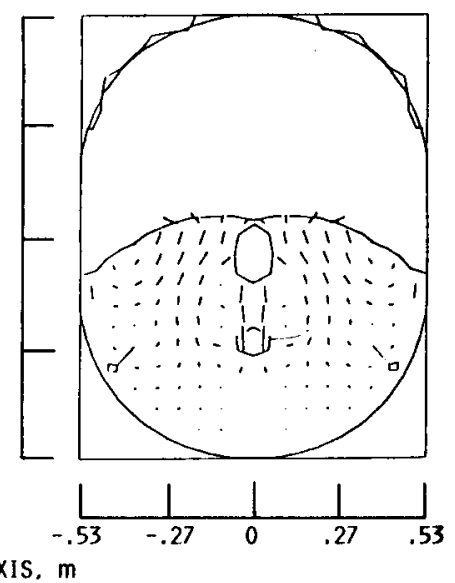

(d) $190 \mathrm{sEC}$.

FIGURE 2. - SETTLING IN 0.25 MODEL OF SB OTV DUE TO OPTIMAL ACCELERATION $\left(a=3.7 \times 10^{-5} \mathrm{~g}\right)$. 


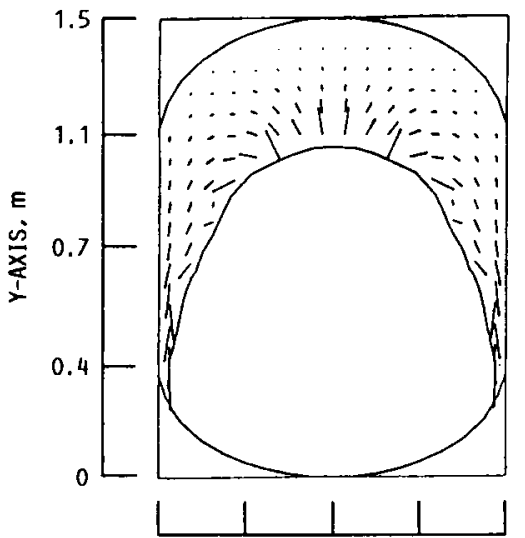

(a) $20.0 \mathrm{sEC}$.

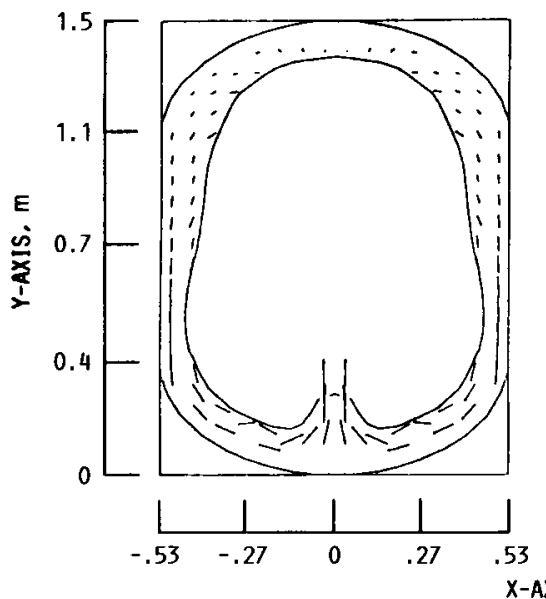

(c) $50.0 \mathrm{sEC}$.

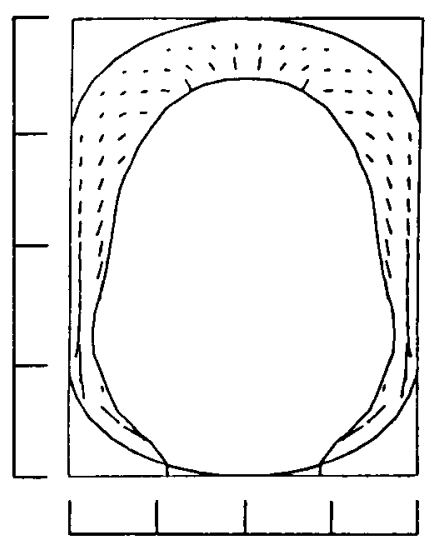

(b) $40.0 \mathrm{sEc}$.

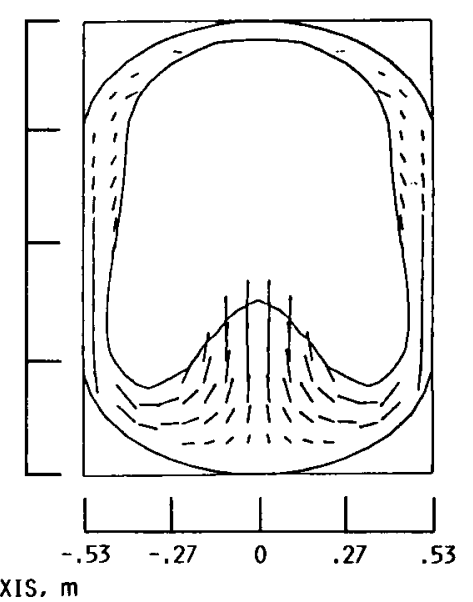

(d) $60.0 \mathrm{sEC}$.

FIGURE 3. - SETTLING IN 0.25 SCALE SB OTV WITH a $=8.0 \times 10^{-3} \mathrm{~g}, t_{p}=0.1$ SEC, $f_{p}=0.1 \mathrm{~Hz}$. 

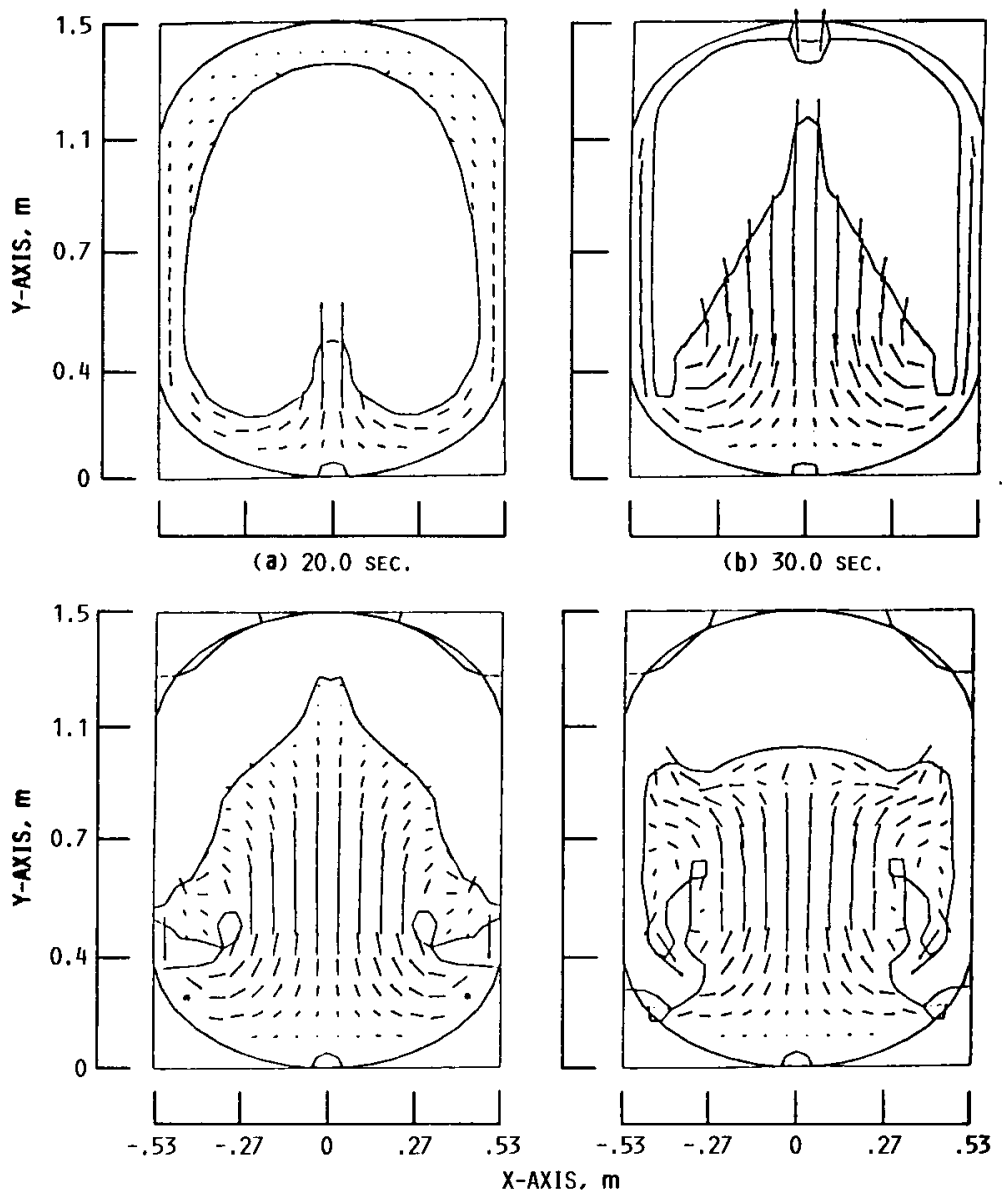

(c) $40.0 \mathrm{sEC}$.

(d) $50.0 \mathrm{sEC}$.

FIGURE 4. - SETTLING IN 0.25 -SCALE SB OTV WITH a $=8.0 \times 10^{-3} \mathrm{~g} \cdot \mathrm{t} p=$ $0.1 \mathrm{sEC}, \mathrm{I}_{\mathrm{p}}=0.7 \mathrm{~Hz}$. 

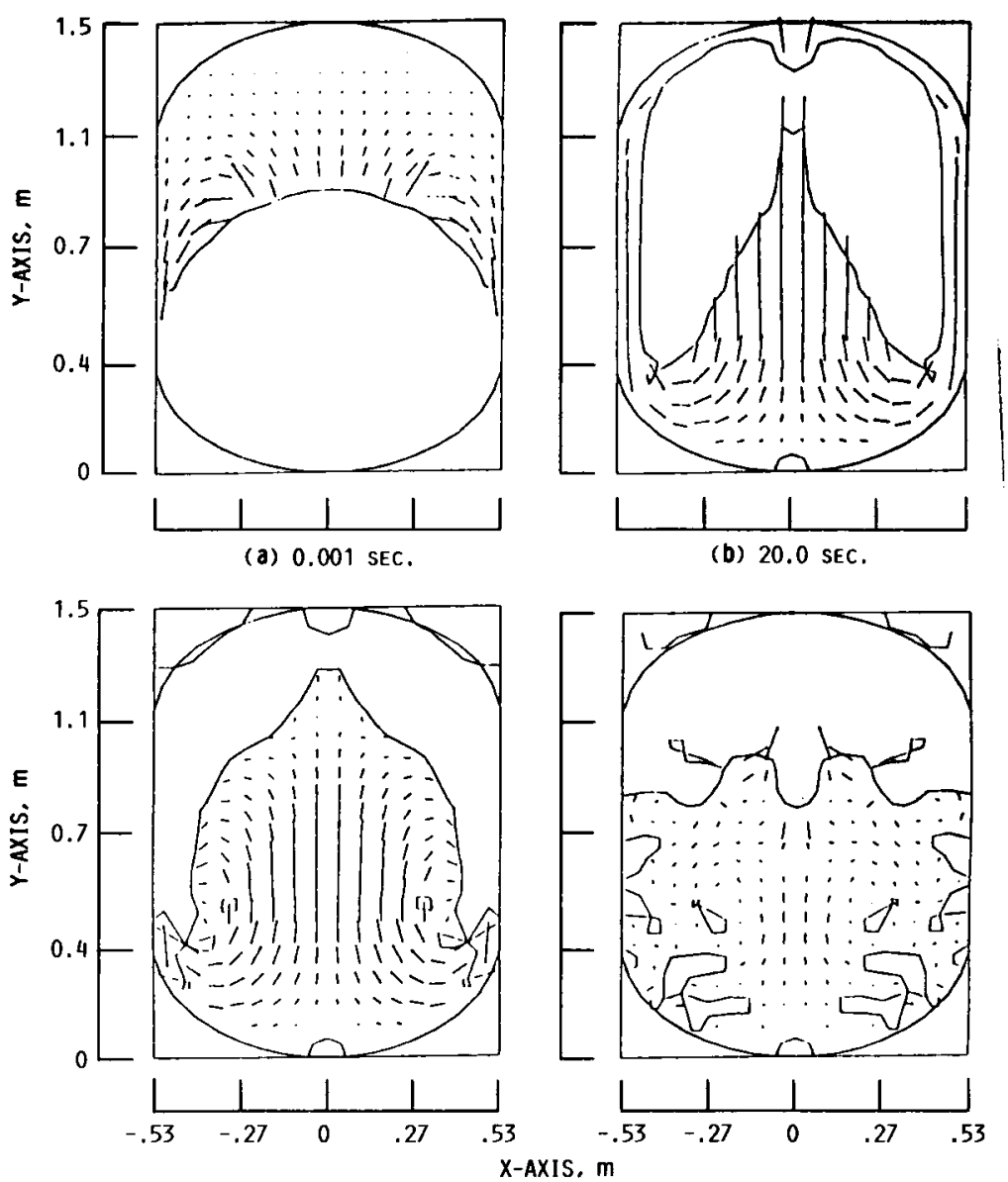

(c) $30.0 \mathrm{sEc}$.

(d) $60.0 \mathrm{sEC}$.

FIGURE 5. - SETTLING IN 0.25 -SCALE SB OTV WITH $a=8.0 \times 10^{-3} \mathrm{~g} \cdot \mathrm{t}_{\mathrm{p}}=$ $0.1 \mathrm{sEC}, f_{p}=1.4 \mathrm{~Hz}$. 


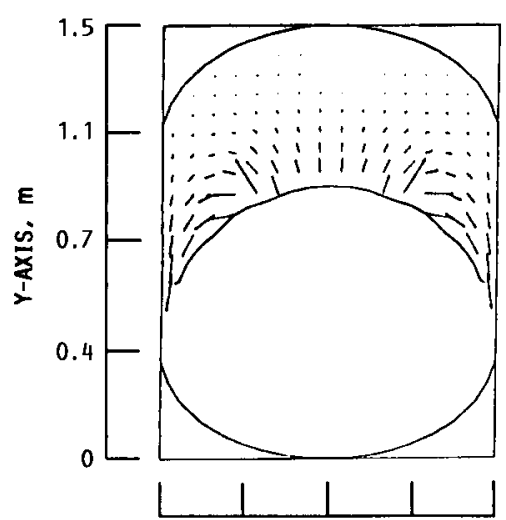

(a) $0.001 \mathrm{sEC}$.

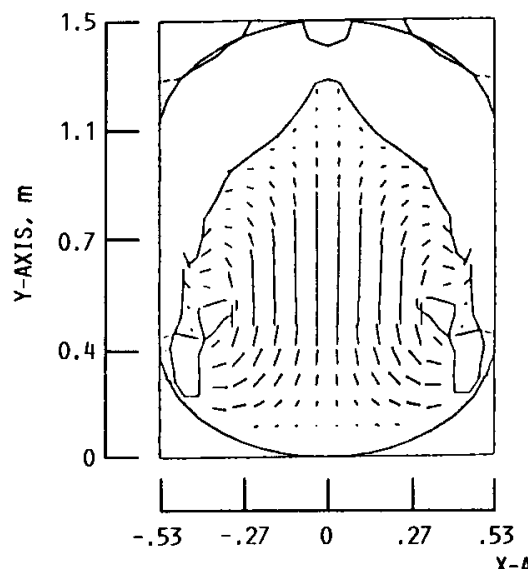

(c) $30.0 \mathrm{sEC}$.

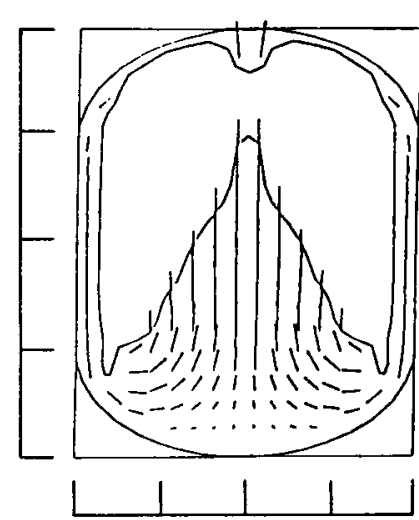

(b) $20.0 \mathrm{sEC}$.

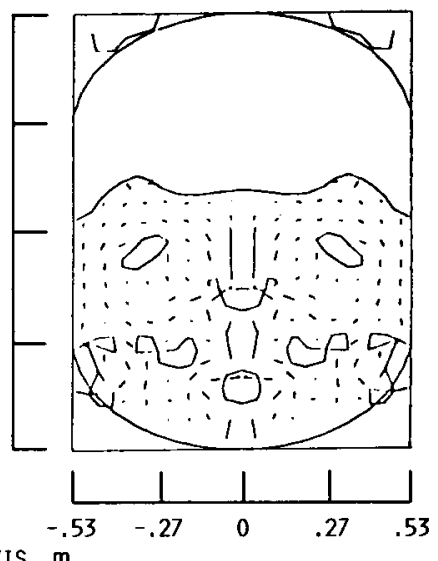

(d) $60.0 \mathrm{sEC}$.

FIGURE 6. -SETTLING IN 0.25 -SCALE SB OTV WITH a $=8.0 \times 10^{-3} \mathrm{~g}, \mathrm{tp}=$ 0.2 SEC, $f_{p}=0.7 \mathrm{~Hz}$.

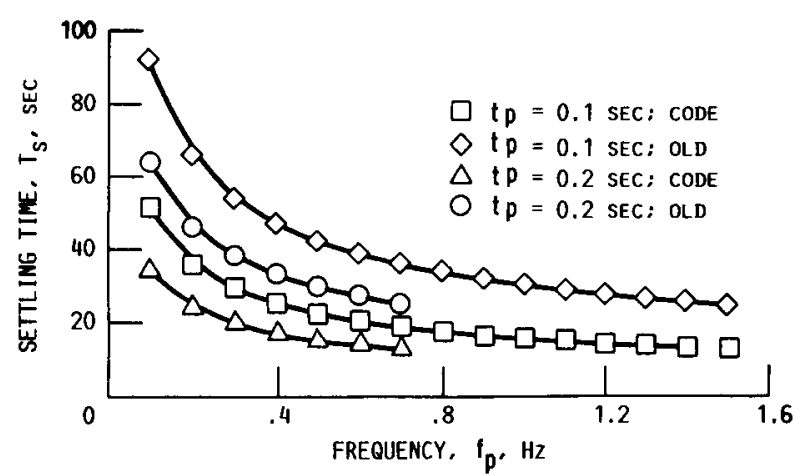

FIGURE 7. - SETTLING TIME VERSUS FREQUENCY, SB OTV, 50 PERCENT FULL.



FIGURE 8. - SETTLING TIME VERSUS VEHICLE VELOCITY INCREMENT, SB OTV, 50 PERCENT FULL. 


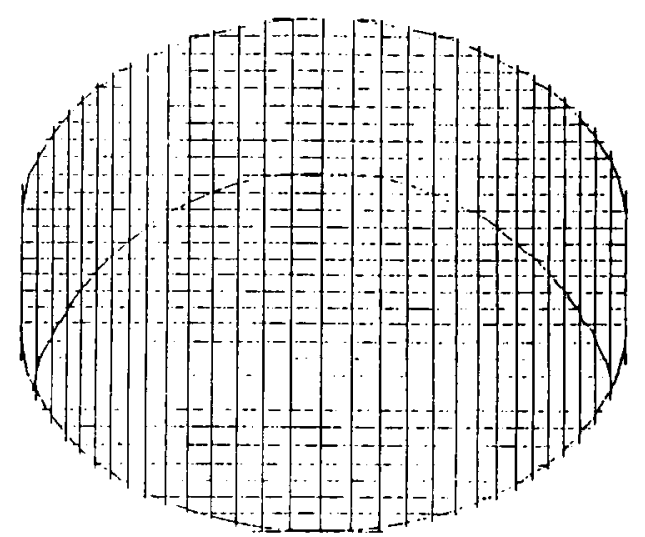

FIGURE 9. - SHORT SB OTV PROPELLANT TANK, FULL SCALE. FINEMESS RATIO $=0.87 ; \mathrm{L}=371.25 \mathrm{~cm}$ : $D=426.72 \mathrm{~cm}$.

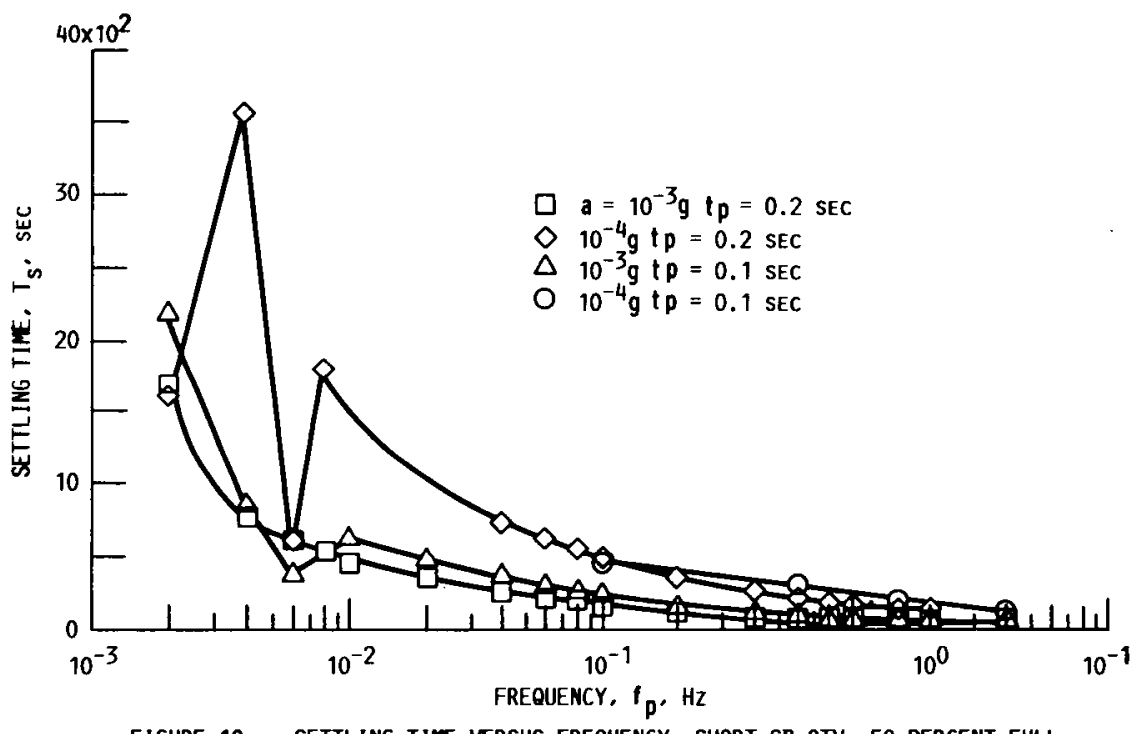

FIGURE 10. - SETTLING TIME VERSUS FREQUENCY, SHORT SB OTV, 50 PERCENT FULL.

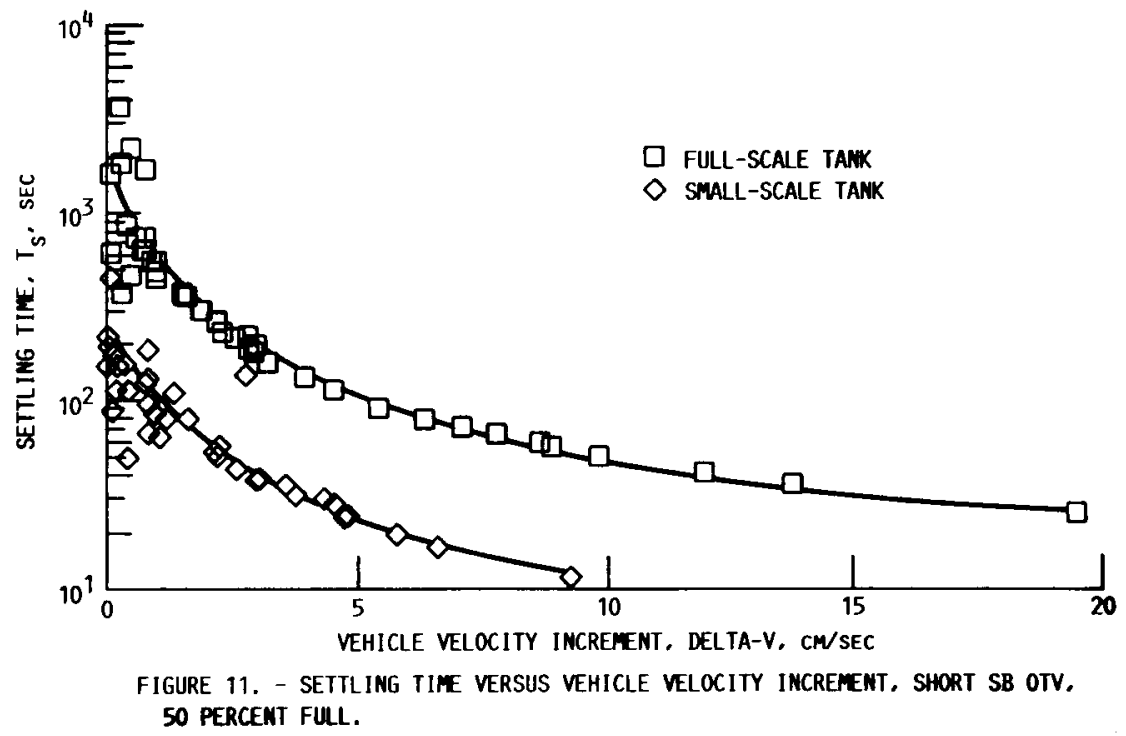




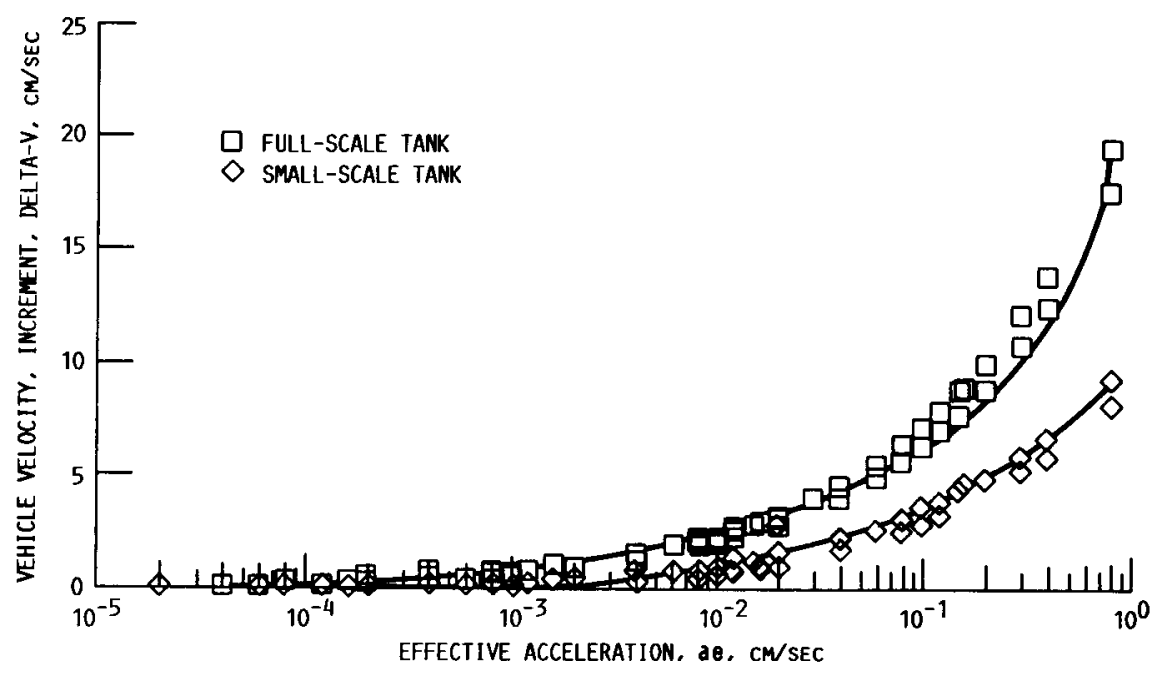

FIGURE 12.- VEHICLE VELOCITY INCREMENT VERSUS EFFECTIVE ACCELERATION, SHORT SB OTV, 50 PERCENT FULL.

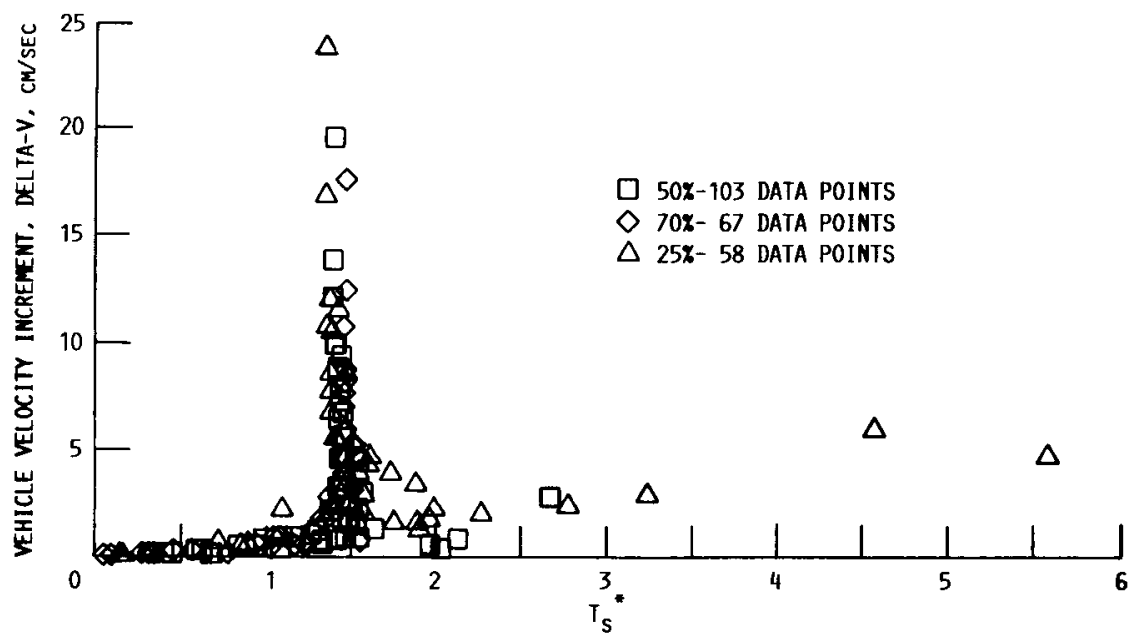

FIGURE 13. - VEHICLE VELOCITY INCREMENT VERSUS $\mathrm{T}_{\mathrm{S}}{ }^{*}$, SHORT SB OTV, ALL FILL LEVELS. 


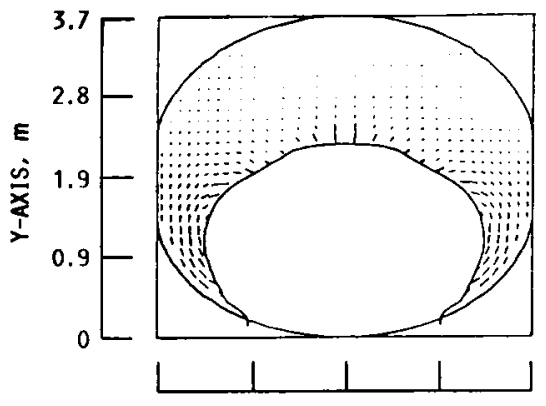

(a) $100.0 \mathrm{sEC}$.

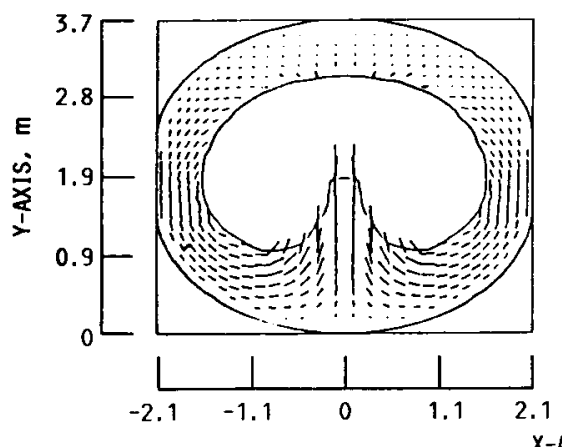

(c) $250.0 \mathrm{sEC}$.

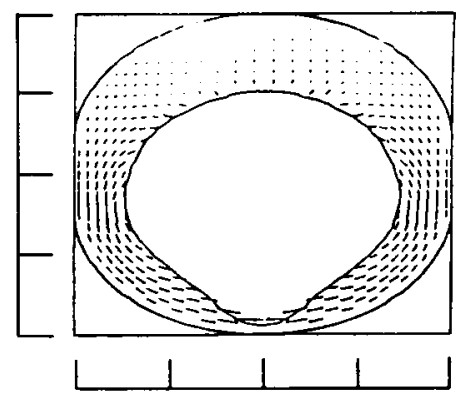

(b) $200.0 \mathrm{sEC}$.

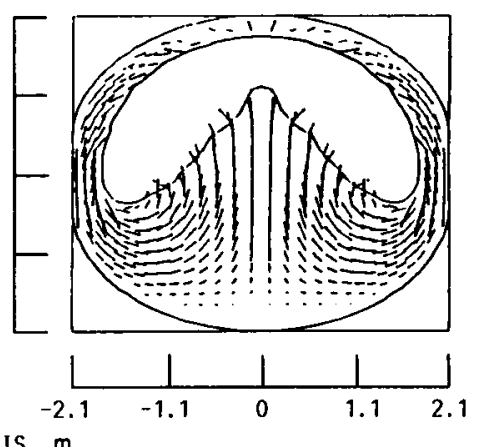

(d) $350.0 \mathrm{sEC}$.

FIGURE 14. - SHORT SB OTV, FULL-SCALE. CASE 1: FILL LEVEL = 70 PERCENT:

$a_{0}=7.85 \times 10^{-3} \mathrm{~cm} / \mathrm{SEC}^{2} ;$ DELTA-V $=1.77 \mathrm{~cm} / \mathrm{SEC} ; \mathrm{T}_{\mathrm{S}}^{*}=1.41 ;$ MODERATE GEYSER.

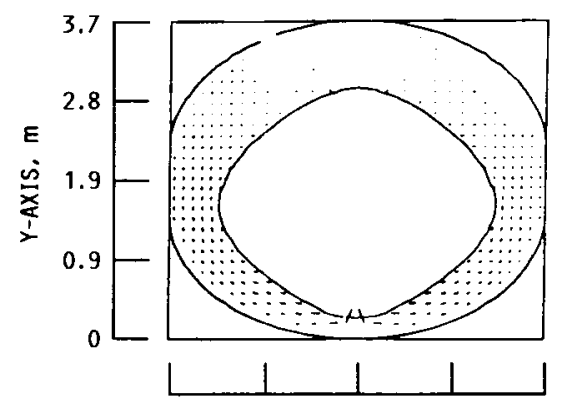

(a) $170.0 \mathrm{sEC}$.

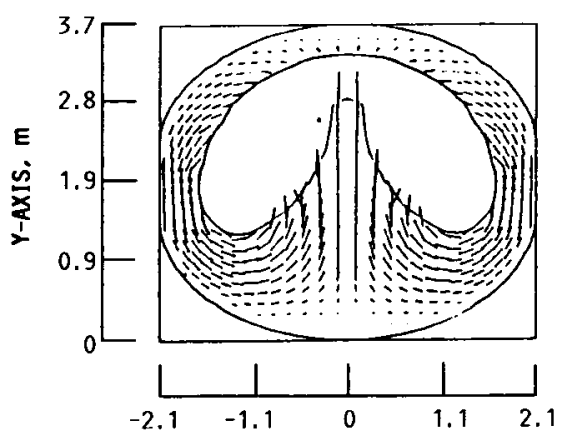

(c) $250.0 \mathrm{sEC}$.

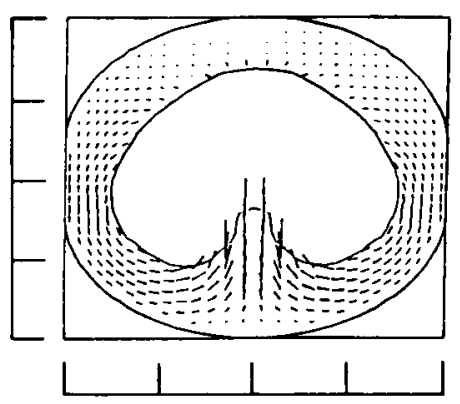

(b) $200.0 \mathrm{SEC}$.

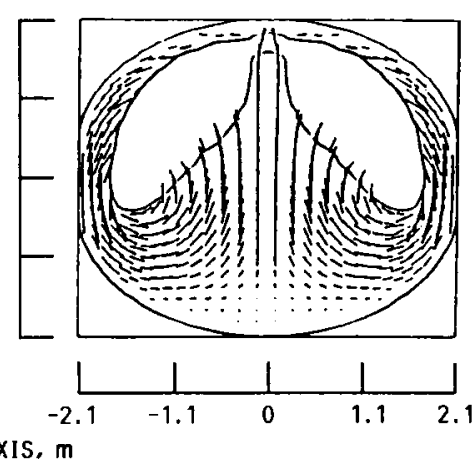

(d) $300.0 \mathrm{sEC}$.

FIGURE 15. - SHORT SB OTV, FULL SCALE. CASE 2: FULL LEVEL = 70 PERCENT: $a_{0}=1.18 \times 10^{-2} \mathrm{~cm} / \mathrm{SEC}^{2}:$ DELTA-V $=2.16 \mathrm{cM} / \mathrm{SEC}: \mathrm{T}_{S}=1.45 ;$ SEVERE GEYSER. 

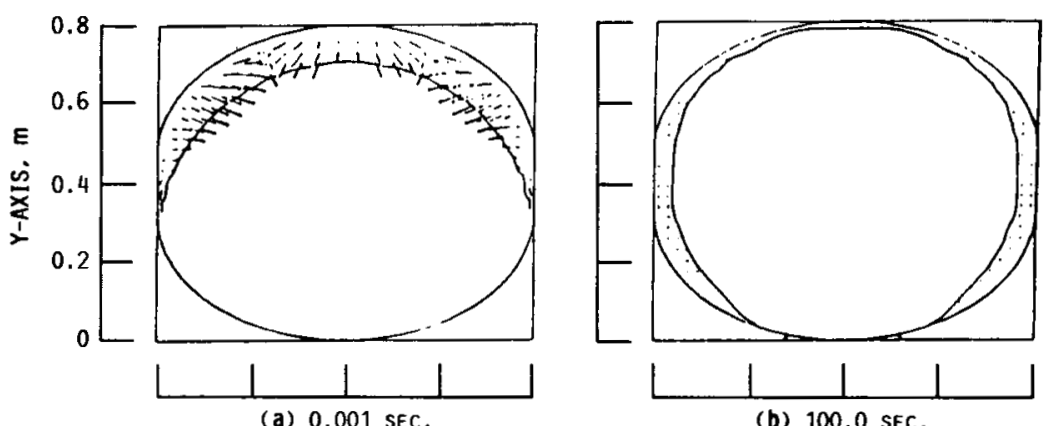

(b) $100.0 \mathrm{sEC}$.
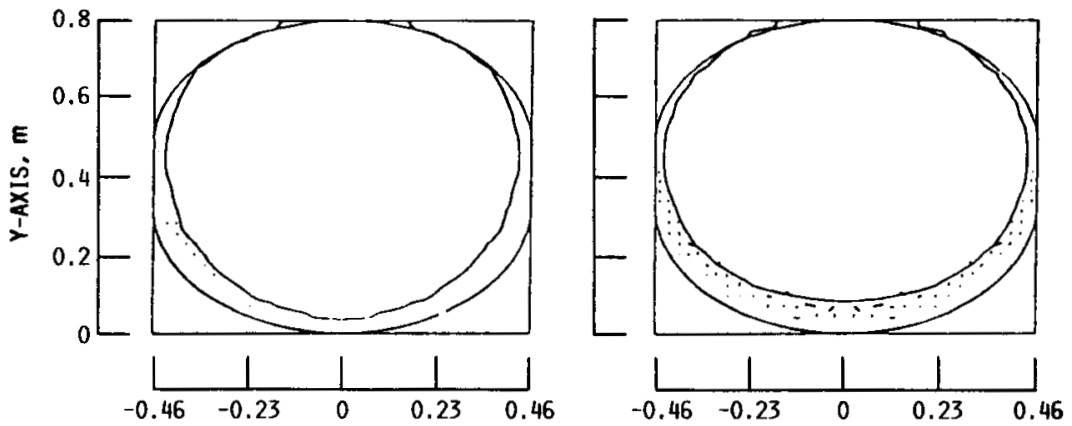

(c) $200.0 \mathrm{SEC}$.

(d) $500.0 \mathrm{sEC}$.

FIGURE 16. - SHORT SB OTV, 0.215 SCALE. CASE 3: FILL LEVEL $=25$ PERCENT: $a_{e}=7.85 \times 10^{-3} \mathrm{cM} / \mathrm{sEC}^{2} ;$ DELTA-V $=4.61 \mathrm{~cm} / \mathrm{SEC} ; \mathrm{T}_{\mathrm{s}}{ }^{*}=5.59$; NO GEYSER. 


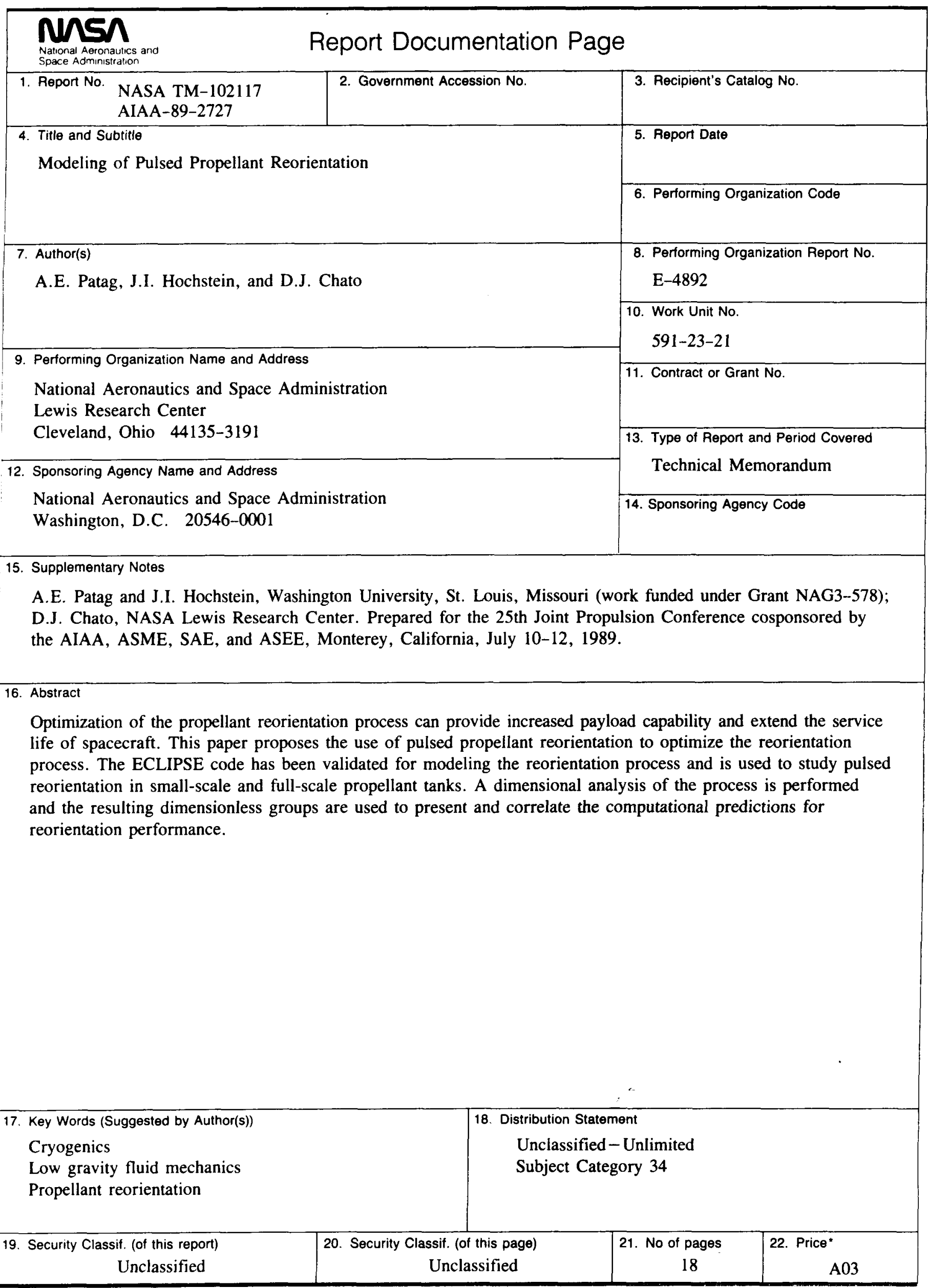

